Tropical Journal of Pharmaceutical Research July 2018; 17 (7): 1379-1384

ISSN: $1596-5996$ (print); 1596-9827 (electronic)

(C) Pharmacotherapy Group, Faculty of Pharmacy, University of Benin, Benin City, 300001 Nigeria.

\title{
Investigation of nedaplatin and CpG oligodeoxynucleotide combination therapy in a mouse model of lung cancer
}

\author{
Jianfeng Quan, Yanli Zhao* \\ Department of Oncology, The Affiliated Hospital of Shanxi University of Chinese Medicine, Weiyang Road, Xianyang, 712000, \\ PR China
}

*For correspondence: Email: yanli_z@yeah.net; Tel: +86-029-32087707

Sent for review: 9 March 2018

Revised accepted: 24 June 2018

\begin{abstract}
Purpose: To investigate the anti-tumor effects of nedaplatin (NDP) and CpG oligodeoxynucleotide (CPG-ODN) combination therapy in a mouse-modeled lung cancer.

Methods: To evaluate the anti-tumor effects of NDP and CpG-ODN combination therapy, a lung cancer xenograft mouse model was established by subcutaneous injection of $L A-795$ cells. BALB/c mice were divided into four groups as follows: NDP, CpG-, NDP + CpG-ODN and untreated control group. The sections of lung cancer tissue were stained with hematoxylin and eosin (H\&E) and morphologically examined. Spleen, body weight, and spleen index were measured. Flow cytometry was used to determine the proportions of $\mathrm{CD}^{+}, \mathrm{CD} 8^{+}, \mathrm{CD} 4^{+}$and $\mathrm{CD4^{+ }} / \mathrm{CD} 8^{+}$in mice blood cells. Serum levels of interferon-y (IFN-y) and interleukin-12 (IL-12) were measured by enzyme-linked immunosorbent assay (ELISA).

Results: $N D P+C p G-O D N$ therapy significantly reduced tumor volume and prolonged the survival time of tumor-bearing mice. NDP + CpG-ODN induced a change in cancer cell morphology, including large areas of necrosis which correlated with a reduction in tumor size. NDP + CpG-ODN significantly increased spleen weight/index and dramatically enhanced immune cell activation. This was evident in the increase serum levels of IFN-y and IL-12.

Conclusion: NDP and CpG-ODN combination therapy inhibits the growth of lung cancer and prolongs the survival time of tumor-bearing mice. This may result from the activation of immune cells and increased expression of IFN- $y$ and IL-12.
\end{abstract}

Keywords: $C p G O D N, N D P$, Lung cancer, Combination therapy

\begin{abstract}
This is an Open Access article that uses a funding model which does not charge readers or their institutions for access and distributed under the terms of the Creative Commons Attribution License (http://creativecommons.org/licenses/by/4.0) and the Budapest Open Access Initiative (http://www.budapestopenaccessinitiative.org/read), which permit unrestricted use, distribution, and reproduction in any medium, provided the original work is properly credited.
\end{abstract}

Tropical Journal of Pharmaceutical Research is indexed by Science Citation Index (SciSearch), Scopus, International Pharmaceutical Abstract, Chemical Abstracts, Embase, Index Copernicus, EBSCO, African Index Medicus, JournalSeek, Journal Citation Reports/Science Edition, Directory of Open Access Journals (DOAJ), African Journal Online, Bioline International, Open-J-Gate and Pharmacy Abstracts

\section{INTRODUCTION}

Lung cancer is a common malignant cancer with high morbidity and mortality rates. Lung cancer frequently results in organ metastasis, leading to death[1]. It is therefore necessary to develop new lung cancer therapy strategies [2].
Nedaplatin (NDP) is a platinum-based anti-tumor drug, which is widely used in chemotherapy to treat a variety of cancers. Its prominent antitumor effects are attributed to its interference with DNA replication, resulting in DNA damage [3]. However, NDP therapy shows some side effects, including bone marrow suppression, renal dysfunction, and immune dysfunction [4]. 
CpG oligodeoxynucleotides (CpG-ODNs), acting as immuno-stimulants, and are composed of single-stranded, non-methylated DNA molecules. Some researchers have demonstrated that CpGODN therapy significantly enhances humoral immunity, activating the patient's immune system, and promoting tumor clearance [5]. However, the effects of NDP + CpG-ODN combination therapy on lung cancer remains unknown. In order to better understand this relationship we established a lung cancer xenograft mouse model to evaluate the effects of $\mathrm{NDP}+\mathrm{CpG}-\mathrm{ODN}$ combination therapy, as well as, the mechanisms of NDP + CpG-ODN combination therapy.

\section{EXPERIMENTAL}

\section{Animals}

BALB/c mice (5 weeks old) were purchased from Luzhou Medical College (Animal Quality Certificate No. SCXK Chuan 2013-17). All animal experiments were performed in accordance with the guidelines of China Council on Animal Care and Use. All animals were maintained and experiments were performed in accordance with the European Community guidelines for the use of experimental animals (86/609/EEC) [6]. The animals were raised at the Department's Animal Experiment Center, The Affiliated Hospital of Shanxi University of Chinese Medicine. All animal procedures were approved by the Emory Institutional Animal Care and Use Committee (approval ref no. SZFYIEC-PJ-201421).

\section{Animal model}

Each mouse was subcutaneously injected with LA-795 cells $\left(10^{6}\right)$ in $0.1 \mathrm{~mL}$ medium (mouse lung adenocarcinoma cell line, obtained from ATCC, Manassas, VA). When the tumor volume reached $80 \mathrm{~mm}^{3}$, sixty mice were randomly divided into 4 groups as follows: control group (no treatment), CpG-ODN group, NDP group, and NDP + CpG-ODN group. All mice received an intravenous injection every two days. In detail, in the control group, the mice received $0.1 \mathrm{~mL}$ PBS. In the CpG-ODN group, the mice received $0.1 \mathrm{~mL}$ CpG-ODN at a dose of $0.5 \mathrm{mg} / \mathrm{mL}$. In the NDP group, the mice received $0.1 \mathrm{~mL}$ NDP (Aladdin Co., Shanghai, China) at a dose of 1 $\mu \mathrm{g} / \mathrm{mL}$. In the NDP + CpG-ODN combination therapy group, the mice received $0.1 \mathrm{~mL} \mathrm{CpG-}$ ODN at a dose of $0.5 \mathrm{mg} / \mathrm{mL}$ and $0.1 \mathrm{~mL} \mathrm{NDP}$ at a dose of $1 \mu \mathrm{g} / \mathrm{mL}$. The sequence of nonmethylated CpG-ODN was ATA ATC GAC GTT CAA GCA AG (Shenggong Co., Shanghai, China). After 22 days of treatment, all mice were held without food overnight. The next day the mice were deeply anesthetized with $\mathrm{CO}_{2}$ and their tissues were isolated.

\section{Therapeutic assessment}

The long diameter/length ( $L$ ) and short diameter/width (W) of the tumor was measured using vernier calipers. According to a previous report [7], tumor volume (V) was calculated as follows: $V=\left(L \times W^{2}\right) / 2$. For the survival experiment, the treatment lasted 22 days. In addition, death of mice was defined by the following conditions: tumor volume $>2000 \mathrm{~mm}^{3}$, mouse weight loss $>20 \%$, or tumor diameter > $20 \mathrm{~mm}$.

\section{Histological examination}

Tumor tissues were fixed in 10\% formalin before being embedded in paraffin and sectioned $(10 \mu \mathrm{m}$ thickness) for histology. The sections were stained with hematoxylin and eosin (H\&E) and images were captured by microscopy.

\section{Evaluation of spleen weight and index}

The spleens were weighed and measured using the following formula: spleen index = spleen weight/body weight.

\section{Immunocyte assay and enzyme-linked immunosorbent assay (ELISA)}

After 22 days of treatment, blood was also collected using a glass capillary tube from the retro-orbital venous plexus under light ether anesthesia. CD3+, CD8+, CD4+ and CD4+/CD8+ were analyzed by flow cytometry. The levels of IFN- $y$ and IL-12 in the serum were measured using ELISA.

\section{Statistical analysis}

Statistical analyses were conducted using SPSS 11.5 (Chicago, IL, USA). All the data are presented as mean \pm standard deviation (SD). Student's t-test and Welch's t-test were used for comparing two groups, while a one-way ANOVA, followed by SNK-q test was used for comparing multiple groups. $P<0.05$ was considered statistically significant.

\section{RESULTS}

\section{NDP and CpG-ODN therapies attenuate tumor growth in tumor-bearing mice}

All treated groups showed slower tumor growth compared to control group. However, from day 10 to day 22, there was a significant increase of 
tumor volume in the NDP + CpG-ODN combination group, compared to the CpG-ODN group and NDP group.

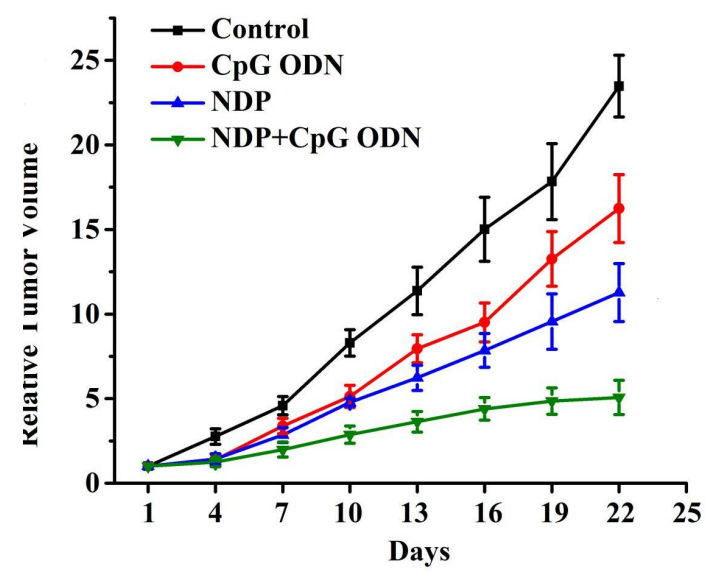

Figure 1: NDP and + CpG-ODN inhibited tumor growth of lung cancer xenograft mice

\section{NDP and CpG-ODN therapies prolong the survival time of tumor-bearing mice}

As shown in Figure 2, the CpG-ODN (31 days), NDP (35 days) or NDP + CpG-ODN combination (43 days) therapy could significantly prolong the survival time compared to the control groups, which averaged 27 days $(p<0.05)$.

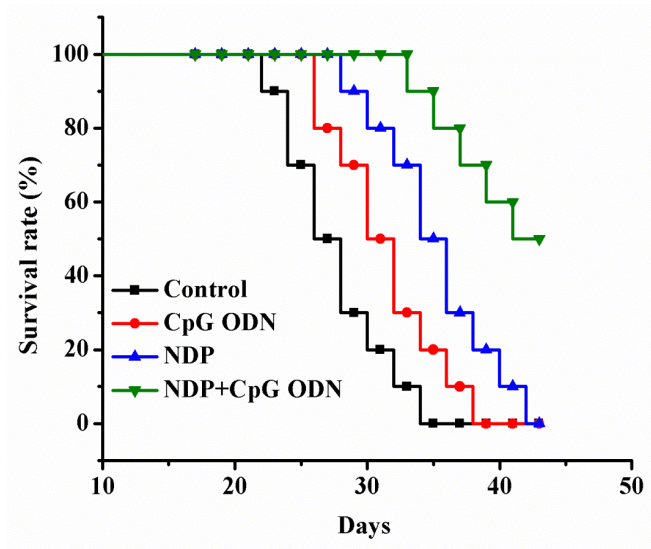

Figure 2: NDP and CpG-ODN therapies prolong the survival time of tumor-bearing mice

\section{Morphological changes in by NDP and CpG- ODN therapies}

As shown in Figure 3, the histopathological evaluation of tumor tissues showed that the tumor cells in the control group were closely arranged, in round shaped without any apoptotic morphological changes. However, in the treatment groups, the histopathological evaluation of tumor tissues showed obvious vacuoles and nucleus pyknosis.

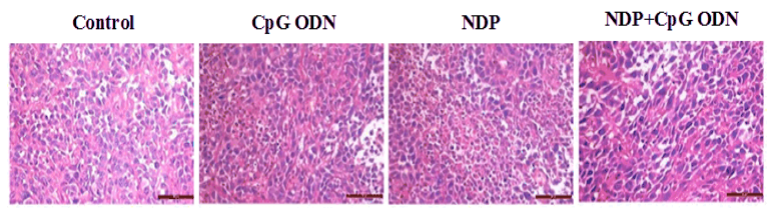

Figure 3: H\&E staining of tumor tissues in different groups (Scale bar $=10 \mu \mathrm{m}$ )

\section{CpG-ODN or NDP + CpG-ODN combination} therapy improve spleen index

As shown in Table 1, the average spleen weight in the CpG-ODN group $(0.34 \pm 0.07 \mathrm{~g})$ was, significantly higher than controls $(0.19 \pm 0.03 \mathrm{~g})$. However, there was no significant difference between the NDP group $(0.17 \pm 0.03 \mathrm{~g})$ and the control group. In addition, the spleen weight in the NDP + CpG-ODN combination therapy group significantly increased compared to the control group and the NDP group. However, there was no significant difference between the NDP + CpG-ODN and CpG group. In addition, the spleen index in both CpG-ODN (20.55 $\pm 2.62 \%)$ and NDP + CpG-ODN group (20.54 $\pm 2.65 \%)$ significantly increased compared to controls $(11.92 \pm 1.87 \%)$. There was no significant difference between NDP and the controls.

Table 1: Spleen index and spleen weight of tumorbearing mice (mean $\pm S D$ )

\begin{tabular}{lcc}
\hline Group & $\begin{array}{c}\text { Spleen weight } \\
(\mathbf{g})\end{array}$ & $\begin{array}{c}\text { Spleen index } \\
(\mathbf{m g} / \mathbf{g})\end{array}$ \\
\hline Control & $0.19 \pm 0.03$ & $11.92 \pm 1.87$ \\
CpG-ODN & $0.34 \pm 0.07^{\mathrm{a}}$ & $20.55 \pm 2.62^{\mathrm{a}}$ \\
NDP & $0.17 \pm 0.03^{\mathrm{b}}$ & $11.89 \pm 1.88^{\mathrm{b}}$ \\
NDP+CpG & $0.33 \pm 0.06^{\mathrm{ac}}$ & $20.54 \pm 2.65^{\mathrm{ac}}$ \\
-ODN &
\end{tabular}

Note: Compared to the control group, ${ }^{a} p<0.05$; compared to the CpG-ODN group, ${ }^{b} p<0.05$; compared to the NDP group, ${ }^{c} p<0.05$

\section{Effect of NDP and CpG-ODN therapies on activation of immune cells}

As shown in Table 2, the amount of $\mathrm{CD}^{+}, \mathrm{CD}^{+}$ and NK cells and the ratio of $\mathrm{CD} 4^{+} / \mathrm{CD}^{+}$in the CpG-ODN group were significantly increased compared to those in the control group $(p<$ 0.05 ), whereas the proportion of $\mathrm{CD} 8^{+}$cells was significantly decreased $(p<0.05)$. However, in the NDP-treated group, the proportion of $\mathrm{CD}^{+}$ cells was significantly increased, while the $\mathrm{CD}^{+}$, $\mathrm{CD} 4^{+}, \mathrm{NK}$ and ratio of $\mathrm{CD} 4^{+} / \mathrm{CD}^{+}$significantly decreased compared to those in the control group. In addition, all cells amount in the NDP + CpG-ODN combination therapy group were significantly higher compared to those in the control group $(p<0.05)$. 
Table 2: Comparison of immune cell populations in tumor-bearing mice in different groups (mean \pm SD)

\begin{tabular}{lccccc}
\hline Group & CD3+ (\%) & CD4+ (\%) & CD8+ (\%) & $\begin{array}{c}\text { CD4+/CD8+ } \\
\text { (Ratio) }\end{array}$ & NK (\%) \\
\hline Control & $36.23 \pm 2.44$ & $21.51 \pm 1.76$ & $16.48 \pm 1.34$ & $1.50 \pm 0.31$ & $15.47 \pm 1.64$ \\
CpG-ODN & $45.17 \pm 3.68^{\mathrm{a}}$ & $27.36 \pm 1.93^{\mathrm{a}}$ & $13.55 \pm 1.06^{\mathrm{a}}$ & $1.98 \pm 0.17^{\mathrm{a}}$ & $21.81 \pm 2.37^{\mathrm{a}}$ \\
NDP & $28.51 \pm 2.07^{\mathrm{ab}}$ & $16.24 \pm 1.54^{\mathrm{ab}}$ & $20.39 \pm 1.71^{\mathrm{ab}}$ & $1.19 \pm 0.19^{\mathrm{ab}}$ & $12.17 \pm 1.02^{\mathrm{ab}}$ \\
NDP+CpG- & $41.04 \pm 2.987^{\mathrm{abc}}$ & $24.62 \pm 1.89^{\mathrm{abc}}$ & $17.04 \pm 1.45^{\mathrm{abc}}$ & $1.71 \pm 0.24^{\mathrm{abc}}$ & $18.83 \pm 1.94^{\mathrm{abc}}$ \\
ODN & 41.045 & &
\end{tabular}

Note : Compared to the control group, ${ }^{a} p<0.05$; compared to the CpG-ODN group, ${ }^{b} p<0.05$; Compared to the NDP group, ${ }^{c} p<0.05$

\section{Effect of NDP and CpG-ODN therapies on cytokine secretion}

The serum levels of IFN-y in the CpG-ODN group were $132.47 \pm 8.57 \mathrm{pg} / \mathrm{mL}$. The serum levels of IFN-y in the NDP + CpG-ODN combination therapy group were $115.02 \pm 7.30$ $\mathrm{pg} / \mathrm{mL}$. The levels of IFN-y in serum in these two groups were significantly increased when compared with those in the control group, which were $64.23 \pm 4.68 \mathrm{pg} / \mathrm{mL}(p<0.05)$. However, the serum level of IFN-y in the NDP group was $57.12 \pm 3.98 \mathrm{pg} / \mathrm{mL}$, which was significantly decreased in comparison to that in the control group $(p<0.05)$ (Table 3$)$.

The serum level of IL-12 in the CpG-ODN group was $451.94 \pm 23.74 \mathrm{pg} / \mathrm{mL}$, which was significantly increased compared to the controls, which were $244.37 \pm 13.26 \mathrm{pg} / \mathrm{mL}(p<0.05)$. The serum levels of IL-2 in the NDP group were also significantly increased compared to those in the control group, at $183.07 \pm 10.55 \mathrm{pg} / \mathrm{mL}(p<$ $0.05)$. The serum level of IL-12 in the NDP + CpG-ODN combination therapy group was $378.41 \pm 18.52 \mathrm{pg} / \mathrm{mL}$, which was significantly increased compared with that of the control group $(p<0.05)$. Additionally, the serum levels of IL-12 in the NDP + CpG-ODN combination therapy group were significantly increased compared to those in the CpG-ODN group $(p<$ $0.05)$.

Table 3: Serum levels of IFN-y and IL-2 in tumorbearing mice in different groups (mean $\pm S D$ )

\begin{tabular}{lcc}
\hline Group & IFN-y (pg/mL) & IL-12 $(\mathrm{pg} / \mathrm{mL})$ \\
\hline Control & $64.23 \pm 4.68$ & $244.37 \pm 13.26$ \\
CpG-ODN & $132.47 \pm 8.57^{\mathrm{a}}$ & $451.94 \pm 23.74^{\mathrm{a}}$ \\
NDP & $57.12 \pm 3.98^{\mathrm{ab}}$ & $183.07 \pm 10.55^{\mathrm{ab}}$ \\
NDP+CpG & $115.02 \pm 7.30^{\mathrm{abc}}$ & $378.41 \pm 18.52^{\mathrm{abc}}$
\end{tabular}

${ }^{2} P<0.05$, CpG-ODN \& controls, ${ }^{\circ} p<0.05$, Compared to NDP group, ${ }^{c} p<0.05$

\section{DISCUSSION}

Lung cancer, as a malignant tumor, is characterized by uncontrolled cell division. It is one of the more common forms of cancer and displays extremely high rates of morbidity and mortality. It is therefore necessary to develop new strategies for lung cancer therapy [8]. We found that NDP + CpG-ODN combination therapy had a significant anti-tumor effect. NDP + CpG-ODN significantly increased the survival time of tumor-bearing mice compared with the control. Moreover, the spleen index has been improved by treatment of NDP + CpG-ODN compared to both control and NDP-treated mice, indicating positive effects of the combination therapy.

NDP is a platinum-based drug, widely used in the treatment of bladder, lung and esophageal cancer. The anti-tumor effects result from an interaction between NDP and nucleosides, forming a nucleoside-platinum complex, which interferes with DNA replication, leading to DNA damage. The glycolate is cleaved as an "active species 1" by hydrolysis after NDP enters into the cells. There are balances among a series of active species, which means active species 1 might also be interconverted. The active species can inhibit both DNA replication and RNA transcription by binding to DNA. This process results in apoptosis and necrosis of cells [9-11]. However, because of a lack of specificity, NDP is not precisely related to cancer cells, which induces normal cell death severe side effects result, including immune suppression, bone marrow hematopoietic dysfunction, and hematologic toxicity.

CpG-ODN, as an immuno-modulator, contains the $\mathrm{CpG}$ sequence and effectively activates dendritic cells which secret a variety of immunologic factors [12]. In our study, we found an increase in spleen weight in the CpG-ODN treated mice. In addition, the numbers of $\mathrm{CD}^{+}$, $\mathrm{CD}^{+}$and NK cells, as well as levels of IFN- $\gamma$ and IL-12 increased in the CpG-ODN group. These findings demonstrated that CpG-ODN enhanced immune function in the tumor-bearing mice. CpG-ODN can activate the NF-KB signaling pathway and induce immuno-stimulation in vivo by binding with toll-like receptor 9 to enter into immune cells[13]. Previouse studies also showed 
that $\mathrm{CpG}-\mathrm{ODN}$ might induce cytokines, such as IFN- $\gamma$ and IL-12, by activating JNK1/2 and p38 pathways [14,15]. IFN-y and IL-12 perform functions on activation of $T$ cells by increasing B7-2 and CD69 expression and further promoting the proliferation and differentiation of $T$ cells $[16,17]$. Additionally, CpG-ODN also activates NK cells $[14,15]$.

This study investigated the combination therapeutic effects according to the advantage of both NDP and CpG-ODN. The combination of NDP and CpG-ODN showed the significant improvement of the efficiency of lung cancer therapy in animal models. Meanwhile, this combination may also decrease the side effects. We did not present a side effects investigation in this study, but we look forward to studying those mechanisms in the future.

\section{CONCLUSION}

The results of this study show that NDP + CpGODN inhibits the tumor growth and prolonged the survival time of tumor-bearing mice via activation of immune cells. The therapeutic changes observed indicate that the combination therapy is a potential treatment strategy for the management of lung cancer and reduction in NDP resistance.

\section{DECLARATIONS}

\section{Conflict of Interest}

No conflict of interest associated with this work.

\section{Contribution of Authors}

The authors declare that this work was done by the authors named in this article and all liabilities pertaining to claims relating to the content of this article will be borne by them.

\section{REFERENCES}

1. Stolz AJ, Harustiak $T$, Simonek J, Schutzner J, Lischke R. Pneumonectomy for non-small cell lung cancer: predictors of early mortality and morbidity. Acta Chir Belg. 2014; 114(1): 25-30.

2. Maclntyre EA, Gehring U, Molter A, Fuertes E, Klumper C, Kramer $U$, Quass U, Hoffmann B, Gascon $M$, Brunekreef $B$, et al. Air Pollution and Respiratory Infections during Early Childhood: An Analysis of 10 European Birth Cohorts within the ESCAPE Project. Environ Health Persp. 2014; 122(1): 107-113.

3. Pang $H$, Feng $T$, Lu HL, Meng QW, Chen XS, Shen $Q$, Dong XQ, Cai L. Efficacy and Safety of Nedaplatin in
Advanced Breast Cancer Therapy. Cancer Invest. 2016; 34(4): 167-172.

4. Vergara C, Martinez-Ferrer A, Fernandez M, Oller JE, De la Morena I, Ybanez A, Valls E, Robustillo M, Vicens $E$, Alegre JJ. Bone Manifestations in Patients with Gaucher Disease. Annals of the Rheumatic Diseases. 2014; 73: 1069-1070.

5. Gershan JA, Barr KM, Weber JJ, Jing WQ, Johnson BD. Immune modulating effects of cyclophosphamide and treatment with tumor lysate/CpG synergize to eliminate murine neuroblastoma. Journal for Immunotherapy of Cancer. 2016; 3: 24

6. Zhang J, Song S, Pang Q, Zhang R, Zhou L, Liu S, Meng $F, W u Q$, and Liu C. Serotonin deficiency exacerbates acetaminophen-induced liver toxicity in mice. Scientific reports. 2015; 5, 12184.

7. Yang $H$, Wang J, Fan JH, Zhang YQ, Zhao JX, Dai XJ, Liu $Q$, Shen YJ, Liu C, Sun WD et al. Ilexgenin A exerts anti-inflammation and anti-angiogenesis effects through inhibition of STAT3 and PI3K pathways and exhibits synergistic effects with Sorafenib on hepatoma growth. Toxicol Appl Pharmacol. 2017; 315: 90-101.

8. Bai Y, Wang YL, Yao WJ, Guo L, Xi HF, Li SY, Zhao BS. Expression of miR-32 in human non-small cell lung cancer and its correlation with tumor progression and patient survival. Int J Clin Exp Patho. 2015; 8(1): 824829.

9. Akiyama $H$, Yamamoto M, Sakashita C, Umezawa $Y$, Kurosu T, Murakami N, Miura O. Therapy-related Leukemia with Inv(16)(p13.1q22) and Type D CBFB/MYH11 Developing after Exposure to Irinotecancontaining Chemoradiotherapy. Internal Med. 2015; 54(6): 651-655.

10. Qiu ZQ, Zhao K. Expression of ERCC1, RRM1 and LRP in Non-small Cell Lung Cancers and their Influence on Chemotherapeutic Efficacy of Gemcitabine Concomitant with Nedaplatin. Asian Pac J Cancer P. 2014; 15(17): 7303-7307.

11. Kawanishi $K$, Miyagi $Y$, Yamamoto J, Miyagi $Y$, Nakamura K, Kodama J, Hongo A, Yoshinouchi $M$, Kudo T. Cytocidal effect and DNA damage of nedaplatin in vitro by simulating pharmacokinetic parameters. Cancer Chemotherapy and Pharmacology. 2001; 47(4): 303-308.

12. Li JY, Li JY, Aipire A, Luo JJ, Yuan PF, Zhang FC. The combination of Pleurotus ferulae water extract and CpGODN enhances the immune responses and antitumor efficacy of HPV peptides pulsed dendritic cell-based vaccine. Vaccine. 2016; 34(31): 3568-3575.

13. Zhang $Y Y$, Lin A, Sui QJ, Hang C, Tian ZG, Zhang J. Phosphorothioate modification of the TLR9 ligand CPG ODN inhibits poly(I:C)-induced apoptosis of hepatocellular carcinoma by entry blockade. Cancer Letters. 2014; 355(1): 76-84.

14. Lee S, Hong J, Choi SY, Oh SB, Park K, Kim JS, Karin $M$, Lee SJ. CpG oligodeoxynucleotides induce expression of proinflammatory cytokines and chemokines in astrocytes: the role of c-Jun N-terminal 
kinase in CpG ODN-mediated NF-kappaB activation. J Neuroimmunol. 2004; 153(1-2): 50-63.

15. Ma C, Muranyi $M$, Chu $\mathrm{CH}$, Zhang $\mathrm{JH}$, Chu WM. Involvement of DNA-PKCS in the IL-6 and IL-12 Response to CPG-ODN is Mediated by Its Interaction with TRAF6 in Dendritic Cells. Plos One. 2013; 8(3).

16. Ruan M, Thorn K, Liu SW, Li SY, Yang WJ, Zhang CY, Zhang CP. The secretion of IL-6 by CpG-ODN-treated cancer cells promotes $T$-cell immune responses partly through the TLR-9/AP-1 pathway in oral squamous cell carcinoma. International Journal of Oncology. 2014; 44(6): 2103-2110.

17. Pradhan P, Qin H, Leleux JA, Gwak D, Sakamaki I, Kwak LW, Roy K. The effect of combined IL10 siRNA and CpG ODN as pathogen-mimicking microparticles on Th1/Th2 cytokine balance in dendritic cells and protective immunity against $B$ cell lymphoma. Biomaterials. 2014; 35(21): 5491-5504. 